\title{
Differential gene expression of glycolytic metabolic proteins in two divergent growing muscles of broiler chicken (Ross 308 genotype)
}

\author{
C. Olomu, T. Parr, J. Brameld and J. Wiseman \\ University of Nottingham, School of Biosciences, Sutton Bonington Campus, Loughborough, Leicestershire, LE12 5RD \\ $U K$
}

Selective breeding has led to a broiler chicken phenotype characterised by a rapid growth rate and a higher proportion of breast muscle relative to body weight at the expense of the leg muscle ${ }^{(1)}$. This increased growth rate is associated with high proportion of fast type fibres in breast muscle and is also seen when comparing the same muscles in broilers to those found in the slower growing layers ${ }^{(2)}$. This fibre type is associated with a high glycolytic capacity. Recent observations in rapidly proliferating cells have indicated that high glycolytic capacity is associated with increased biosynthetic potential, such as the synthesis of the non-essential amino acid serine and associated metabolites ${ }^{(3)}$. The aim of this study was to determine if there was an association between leg and breast muscle growth and expression of genes coding for glycolytic enzymes (Glyceraldehyde-3-phosphate dehydrogenase (GAPDH), Enolase) as well as the closely related serine biosynthesis pathway consisting of phosphoglycerate dehydrogenase (PHGDH), phosphoserine aminotransferase (PSAT) and phosphoserine phosphatase (PSPH).

Eighteen male broiler chickens were raised on a standard broiler feed and breast (Pectoralis major (PM)) and leg (Peroneus tertius (PT)) muscles were collected at 14, 36 and 43 days post-hatch. Total RNA was extracted using QIAGEN RNeasy fibrous tissue mini kit. First strand cDNA was generated using random primers and a Roche transcriptor kit. Primers were designed using primer express software. The mRNA expression relative to cyclophillin (no treatment effect on cyclophillin expression) was determined by quantitative RT-PCR analysis (Roche 480 lightcycler).

\begin{tabular}{|c|c|c|c|c|c|c|c|c|}
\hline \multirow[b]{2}{*}{ Measurement } & \multirow[b]{2}{*}{ Muscle } & \multicolumn{3}{|l|}{ Day } & \multirow[b]{2}{*}{$\mathrm{SED}^{\mathrm{a}}$} & \multicolumn{3}{|c|}{ Effect (P value) } \\
\hline & & $\overline{14}$ & 36 & 43 & & Muscle & Age & Muscle $\times$ age \\
\hline \multirow[t]{2}{*}{ Muscle wt (g) } & $\mathrm{PM}$ & 21 & 149 & 170 & $4 \cdot 3$ & $<0.001$ & $<0.001$ & $<0.001$ \\
\hline & PT & 1 & 14 & 12 & & & & \\
\hline \multirow[t]{2}{*}{ Enolase mRNA ${ }^{b}$} & PM & 3.65 & 4.40 & $3 \cdot 51$ & 0.71 & $0 \cdot 012$ & $0 \cdot 223$ & 0.003 \\
\hline & PT & 1.78 & $2 \cdot 00$ & $0 \cdot 50$ & & & & \\
\hline \multirow[t]{2}{*}{ 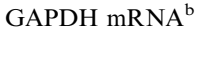 } & PM & 1.41 & $3 \cdot 52$ & 1.60 & $0 \cdot 81$ & $0 \cdot 047$ & $0 \cdot 026$ & $0 \cdot 545$ \\
\hline & PT & 0.71 & 1.49 & $0 \cdot 50$ & & & & \\
\hline \multirow[t]{2}{*}{ PHGDH mRNA ${ }^{b}$} & PM & $6 \cdot 89$ & $29 \cdot 71$ & $4 \cdot 78$ & 0.92 & 0.006 & $<0.001$ & $0 \cdot 036$ \\
\hline & PT & 2.47 & $7 \cdot 37$ & 1.63 & & & & \\
\hline \multirow[t]{2}{*}{ PSAT mRNA ${ }^{b}$} & $\mathrm{PM}$ & 1.04 & $7 \cdot 15$ & $1 \cdot 14$ & $1 \cdot 10$ & $0 \cdot 191$ & $0 \cdot 020$ & 0.097 \\
\hline & PT & 0.48 & $2 \cdot 00$ & 0.50 & & & & \\
\hline \multirow[t]{2}{*}{ PSPH mRNA ${ }^{b}$} & $\mathrm{PM}$ & $3 \cdot 81$ & $6 \cdot 70$ & $3 \cdot 95$ & 1.05 & 0.008 & 0.578 & $0 \cdot 578$ \\
\hline & PT & $1 \cdot 34$ & 1.78 & 0.89 & & & & \\
\hline
\end{tabular}

Values are means, $\mathrm{n}=6$ animals per time point. Significance accepted where $\mathrm{P}<0 \cdot 05$, two way ANOVA (Genstat). ${ }^{\mathrm{a}} \mathrm{SED}=$ standard error of the differences of the means. ' mRNA expression was normalised to cyclophillin.

As expected, the weight of PM was significantly greater than PT at all ages. Expression of all genes (except for PSAT) was significantly higher in PM than PT. The expression of all genes tended to peak at day 36 post-hatch, potentially reflecting the end of the period for rapid growth. The current study indicates that elevated expression of glycolytic and serine biosynthetic pathways, previously associated with hyperplastic growth ${ }^{(3)}$, are also observed in chicken breast muscles and therefore associated with fast fibre hypertrophic growth.

1. Al-Musiwa SL, Lock F, Simbi BH et al. (2011) Differentiation 82, 127-135.

2. Zheng Q, Zhan Y, Chen Y, et al. (2009) BMC Genomics 10, 87.

3. Amelio I, Cutruzzola F, Antonov A et al. (2014) Trends Biochem Sci 39, 191-198. 